\title{
Training practices and Organizational Commitment in the Yemeni Islamic Banking Sector: The Mediating Role of Tribalism
}

\author{
Ali Salman Emam \\ Juraifa Bte Jais \\ Universiti Tenaga Nasional, Malaysia \\ Mosab I. Tabash \\ College of Business, Al Ain University of Science and Technology, UAE
}

\begin{abstract}
Keywords
Training practices - Organizational Commitment- Tribalism- Yemen Islamic Banks Sector.
\end{abstract}

\begin{abstract}
This study conducted in the Yemeni Islamic banking sector. The purpose of this study is to determine the relationship between Training practices as independent variables and Organizational Commitment as a dependent variable through Tribalism Relations as a mediating variable. The search focuses on employees, departmental guidelines and career development practices and their relationship to the level of commitment displayed by the employees. The quantitative design was used in this study to test hypotheses. 450 questionnaires were distributed to various employees in four Islamic banks in Yemen. 292 valid questionnaires were collected, representing $65 \%$, which is acceptable in scientific research. Smart PLS-SEM technique is used to validate the measurement model and structural model which significantly contributes to the methodological aspect. The findings reveal that there is a significant impact on Training practices, and Organizational Commitment. Moreover, the results show that Tribalism is playing an important role as mediator on the relationship between Training practices and Organizational Commitment in the Islamic banking sector in Yemen.
\end{abstract}

Corresponding author: Ali Salman Emam

Email addresses for the corresponding author: ali.salman808@yhoo.com

The first submission received: $12^{\text {th }}$ May 2018

Revised submission received: $20^{\text {th }}$ September 2018

Accepted: $10^{\text {th }}$ October 2018

\section{Introduction}

Organizational Commitment (OC) has received more attention in organizational research and practices because of its positive outcomes (Imran, Arif, Cheema, \& Azeem, 2014). Many research has been done to exam the antecedents of commitment to finding the most significant factors that determine OC. Earlier studies (Meyer \& Allen, 1997) suggested that there are many antecedents of OC such as work experiences, personal and organizational factors, and human resource practices. Most of the literature, however, focused on developed countries(Chew \& Chan, 2008; Yamao \& Sekiguchi, 2015), while others have examined the effect of the practices of Training practices on OC among the emerging nations (Aladwan, Bhanugopan, \& D’Netto, 2015; Lamba \& Choudhary, 2013; Nik Ab.Rahman \& Sharmin Shahid, 2009). Indeed, third world countries have a unique context that differs from the developed countries context. Thus, there is a call for research to revitalize Training practices in all cultural contexts.

In line with the discussion, Arabic countries possess unique social and cultural values that deeply effect on managerial functions (Aladwan et al., 2015). Altarawneh (2009) reported that the behaviours of individuals and managerial practices in Arabic countries are significantly affected by the cultures of these countries. In previous studies, the culture was found as an important mediator among the various stakeholders (Aladwan et al., 2015; Yamao \& Sekiguchi, 2015; Zaitouni et al., 2011). Tribalism remains a major cultural factor in many Arab countries, particularly in Yemen. Tribalism in Yemen is responsible for underdevelopment and corruption, serving as a great obstacle that impedes democracy and socioeconomic development (Baabbad, 2015; Fattah, 2011). It is argued that with the presence of Tribalism, the 
commitment and loyalty to tribe will be greater than the commitment and loyalty to the country or organization (Manea, 1996a). Therefore, it is expected that this study contributes to enriching the literature by investigating the influential culture impact on the Training practices and OC relationship in developing countries context such as Yemen. Therefore, importing the Western Training practices to third world countries like Arab countries by neglecting the differences in cultural context could be unreasonable.

Further, there is a gap in the previous literature in terms of examining the effect of training practices on commitment where inconsistent results are found. Another gap that can be extracted from the literature is the factors which might strengthen or weaken the relationship among the training practices and OC. However, the impact of Tribalism as unique characteristics in the Yemeni context is not yet examined, in which Yemen is considered as the poorest country in the Arab region with a strong Tribalism.

Therefore, this study examines the mediating impact of Tribalism on the relationship between training practices, and organizational commitment among the Islamic banks in Yemen. The banking sector is selected because it is considered as a leading driver of economic growth and development by academics and practitioners.

\section{Underpinning Theory}

This study contains the social exchange theory that has employed in the literature to explain the framework of the study to link the relations between Training practices, OC and Tribalism. The concept of social exchange theory is based on the norm of reciprocity (Gouldner, 1960). This theory is used as the theoretical foundation to understand organizational relationships in the organization (Coyle \& Conway, 2005). According to social exchange theory, employees show engaged motivation behaviour when they are given benefits and resources. Accordingly, when the organization takes care of employees through the implementation of HRM practices, employees show more engaged behaviour to their work, leading to better performance outcomes in the workplace and high OC. This study explores a reciprocal exchange of relationship that reflects relative dependency on each other by examining the impact of training practices on $\mathrm{OC}$ in the Islamic banking sector within Yemeni tribal society.

\section{Literature Review Organizational Commitment (OC)}

Organizational Commitment is a complex phenomenon (Meyer \& Allen, 1991), and OC has been developed in the literature on industrial and organizational psychology (Cohen, 2003). OC can be understood as a pattern of behaviour, and a motivating force (Frank \& Goulet, 2002). Foote (2005) stated that $\mathrm{OC}$ is widely described as a key factor in building organizational relationships between individuals and organizations. Yamao and Sekiguchi (2015) stated that OC could be defined as the relative strength of the individual related to the achievement goals of the organization. Sager \& Johnston (1989) claim that the way OC is dealt with is depending on the approach to the commitment that one adheres to. Palmer (2006) stressed that there are two models that dominate the concept and measurement of OC: The first model is Mowday, Porter and Steers model (1974) which is called the attitudinal model. The attitudinal model initiated by Porter et al. (1974) is the most famous model in conceptualizing OC. A decade later, Suliman (2000) showed that four main models conceptualize and explore OC, namely the attitudinal model, the behavioural model, the normative model, and the multidimensional model. Palmer (2006) explained that researchers criticize these models because the concept is general and lacks precision.

The second model is the Allen and Meyer model; it emerges as strongly as an alternative to Mowday and others. It was proposed both as an alternative definition and measurement. It emerged from several works (Allen \& Meyer, 1996; Meyer et al., 2002). According to this viewpoint, OC is the feeling of obligation to stay with the organization: feelings that are resulting from the internalization of normative pressures exerted on an individual before entry or following entry (Allen \& John, 1990). This conceptualization of Meyer and Allen (1991) has become a widely accepted theoretical framework for several research studies (Allen \& Meyer, 1996). This model identified three different components of OC, which are Affective commitment, Continuance commitment, and Normative Commitment 


\section{Tribalism in Yemen}

In general, the tribe also is considered the basic social unit in the Arabian Peninsula (Manea, 1996). Some studies suggest that the tribes about $85 \%$ of the population in Yemen (Brandt, 2017). In Yemen, the tribe is the basic social unit. Tribalism in Yemen has a social and political significance since it constitutes the main point of customs and traditions for most Yemeni people (Corstange, 2008; Robinson et al., 2006). A Yemeni tribe is a corporate unit which has maintained its social and cultural responsibilities (Brandt, 2017). Tribalism in Yemen gives protection assurance to members of the tribe; therefore, tribesmen protect and help each other when there is a need to do so. Rights and benefits from tribalism membership are enjoyed by the tribesmen who in turn have responsibilities to perform (Al-Dawsari, 2012).

\section{Training and Organizational Commitment}

Many studies have shown HRM practices had a significant positive relationship with OC (Jardali et al., 2009; Payne \& Huffman, 2005; Victoria, 2006). For example, Lamba \& Choudhary (2013) revealed that HRM practices provide an edge to employee's commitment towards an organization goal in the global competitive market in the various sector in India. Similarly, a study of Chinese private-owned IT enterprises indicated that four dimensions like information sharing, training and development, recruitment and selection, and compensation management had a positive effect on IT employees' OC (Qiao, Luan, \& Wang, 2008). Also, there are many studies that found the mediating effect of relations between HRM and OC. For example, Zaitouni et al. (2011) found cultural factors and social dimensions as different customs and traditions in the banking sector in Kuwait that had an influence of HRM on OC. Yamao \& Sekiguchi (2015) found language is one of the important cultural factors in Japan. HRM practices that promote learning a foreign language have direct and interactive effects on the affective and normative commitment to their firms' globalization through HRM practices. Aladwan et al. (2015); Chan (2008); and Yamao \& Sekiguchi (2015) examined that effects of HRM practices on OC in the Middle Eastern context. Their findings indicated that the causal model is consistent with the data and contributed to a fuller understanding of the association between HRM practices and OC.

Training and developing employees are increasingly recognized as an important aspect of best HRM practices (Wetland, 2003). Previous empirical studies have provided extensive evidence that training and development facilitate the skills updating, increased commitment, well-being and sense of belonging, strengthening the organization's competitiveness (Acton \& Golden, 2002). Tzafrir (2006) assured that training and development are closely associated with work values, performance and OC. Further, research was conducted in Turkey revealed that all dimensions of training positively affected employee commitment (Bulut \& Culha, 2010). Yap et al. (2009) found an association between employees' perceptions of diversity training and effectiveness with OC, and career satisfaction. The survey conducted in nine large organizations in Canada. The study showed that employees who perceived diversity training were significantly more committed to their organizations and more satisfied with their careers than employees who didn't have diversity training. Another study was conducted in the Western part of China on training and development showed that training is positively related to OC and employability (Ling, 2012). According to the above discussion, the following hypothesis is proposed.

H1: There is a significant relationship between Training and Development and OC to employees in the Yemeni Islamic banking sector.

\section{Tribalism, Training practices, and Organizational Commitment}

Alesina, et al. (2000) state that a tribal identity hurts industrial productivity. By amplifying the positive characteristics of tribalism members and denigrating non-tribalism members, employees "protect, enhance, or achieve a positive social identity" for themselves and members of their in-group (Tajfel \& Turner, 1979). Consequently, they may be less likely to accept, endorse, or interact with non-tribalism members. Hofstede \& Minkov (1997) revealed that collectivism as a cultural dimension refers to that the people act mainly as members of a lifelong and coherent group. Also, the people have large outspread families, which are used as a safeguard in exchange for unquestioning allegiance (Baabbad, 2015). This tribalism customs reflect the interdependence between members of the tribe. Arab countries like Yemen has a unique societal structure with varying tribes. 
In Yemen, the tribalism customs encapsulate the interests of the tribe and its members, where the environment for business is largely controlled and led by varying traditions like customs, rules, norms and attitudes towards social activities and practices (Al-Dawsari, 2012). Literature of in-group and outgroup behaviours suggests that tribalism identity is likely to be negatively related to the HRM in organizations (Zoogah, 2016). Manea (1996) found the tribalism identity of employees is likely to impact their interactions in organizations. In this regard, some tribes in Yemen have a social connection in the form of confederation, where they behave as members of a single tribe (Baabbad, 2015). Therefore, these relations may threat the forming of Training practices, and the commitment especially when the resources and some employees are from similar tribes that have a friendly-social connection. Thus, this study investigates the impact of Tribalism on the employees' commitment and the mediating effect of Tribalism on the relationship between the training practices, and OC. Thus, the following hypotheses are formulated.

H2: There is a significant relationship between Tribalism and OC in the Yemeni Islamic banking sector.

H3: There is a significant relationship between Training and Development and Tribalism in the Yemeni Islamic banking sector.

H4: The Tribalism has a mediating effect on the relationship between Training and Development and organizational commitment in the Yemeni Islamic banking sector.

\section{The Framework}

Based on the previous literature, the variables have been selected for the study which is presented in the framework as shown in Figure 1. Social exchange theory is used to develop the research model. Figure 1 demonstrates the relationship between the dependent variable (Organizational Commitment), independent variables (Training practices) and mediating variable (Tribalism). In line with Allen, Shore, \& Griffeth (2003) positive perceptions of training practices are expected to lead to increasing OC.

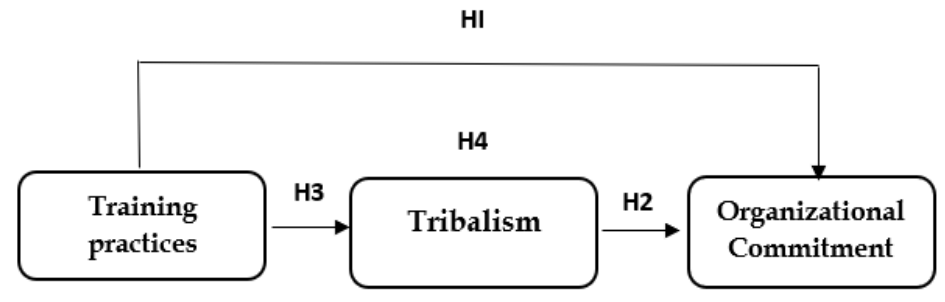

\section{Methodology}

Figure1: Framework of the Study

This study is conducted in the Yemeni Islamic bank's sector. This study is based on quantitative approaches. The study used questionnaires to obtain personal and social facts, beliefs and attitudes (Pedhazur, 1997). The questionnaires are distributed to employees of four Islamic banks in Yemen. The target population of this study focuses on three regions which are selected from the north, middle and south of Yemen, representing the employees in the Islamic banking sector in Yemen (2261 employees). The random sampling technique is used because it has the least bias and offers the most generalization (Cooper \& Schindler, 2006; Sekaran, 2003). Since that population of more than 2200 employees, the minimum sample size of 331 is enough for any research as suggested by many scholars (Sekaran \& Roger, 2010), as shown in Table 1.

Four hundred fifty questionnaires are distributed, the data were collected using the survey questionnaire throughout three-months, 292 usable questionnaires are collected, accounting for $65 \%$ valid response rate which is adequate for the study (Sekaran \& Roger, 2010). Data analysis and hypotheses testing are done through using Partial Least Squares Structural Equation Modeling (PLS-SEM).

Table 1 sampling Frame and Sample Size 


\begin{tabular}{llll} 
Regions & Population & Percentage \% & Sample size \\
North & 855 & $38 \%$ & 126 \\
Middle & 715 & $32 \%$ & 106 \\
South & 691 & $30 \%$ & 99 \\
Total & 2261 & $100 \%$ & 331 \\
\hline
\end{tabular}

\section{Measurement}

There are three variables in this study, namely: Training practices as the independent variables, OC as the dependent variable, and Tribalism as the mediator variable. A five-point Likert's scale is adopted ranging from: "totally disagree" to "totally agree" ( Cavana et al. 2001). The measurements of these three variables are performed according to the recommendations from various sources as follows: Firstly: It is developed based on a modified measurement of training practices from the previous training practices studies that measuring TD in Islamic banking in Yemen (Delery \& Doty, 1996; Fiona E and Alan, 2005). Thus, the measurement of TD consists of 7 items. Secondly, OC is measured by using threedimensional models of OC which is developed, validated and revised by Allen \& Meyer, (1993), the measurement of OC consists of 18 items. Thirdly, the measurement of Tribalism consists of 9 items as appendix shown in appendix 1 . The questionnaire items for measurement of tribalism were adapted from organizational culture measure (Glaser, Susan; Zamanou, 1987).

\section{The Results of the Study}

\section{Assessment of PLS-SEM Model Finding}

In this study, we used the software package PLS-SEM, version 3.0 to test model assessment (Ringle, Christian, Wende, Sven, \& Becker, 2014). This software has been widely used by many researchers from different administrative sciences specializations and organizational behaviour (Henseler et al., 2009). In this study, we adopted the two-step process: (a) Assessment of Measurement Model (b) Assessment of Structural Model (Hair et al., 2014; Henseler et al., 2009). The assessment of the research model is shown in Figure 2.

\section{Assessment of Measurement Model}

The guarantee the validity and reliability of the output of the analysis using the PLS-SEM technique, the goodness of the measurement were evaluated. According to for Hair et al., (2014) and Henseler et al.,(2009), this study assessed indicator reliability, internal consistency reliability, convergent validity and discriminant validity before testing the hypotheses of the model.

As recommended by many researchers, the individual item reliability was examined according to outer loadings of each measure intended to measure a construct where the factor loading of items should be significantly higher than 0.70 (Hair et al., 2011; Henseler et al., 2009). Furthermore, it has also been indicating that composite reliability between 0.60 and 0.70 . Table 2 shows the individual item reliability. Cronbach's alpha is used to underestimate the internal composite reliability of the measures. So, it is suggested as a way to measure the internal consistency reliability (Hair et al., 2014). Hair et al., (2011) indicated that the Cronbach's alpha values and Composite Reliability should be significantly higher than 0.70. In this study, as shown in Table 2. It is clear that the internal consistency reliability of the measures was verified. For establishing adequate convergent validity, the Average Variance Extracted (AVE) is used in which refers to the average percentage of the variance extracted among the observed variables of a construct (Hair et al., 2014). According to Valérie, (2012); and Hair et al., (2014), it should be higher than 0.50 . Table 2 illustrates that all the values of AVE were in the acceptable region. 


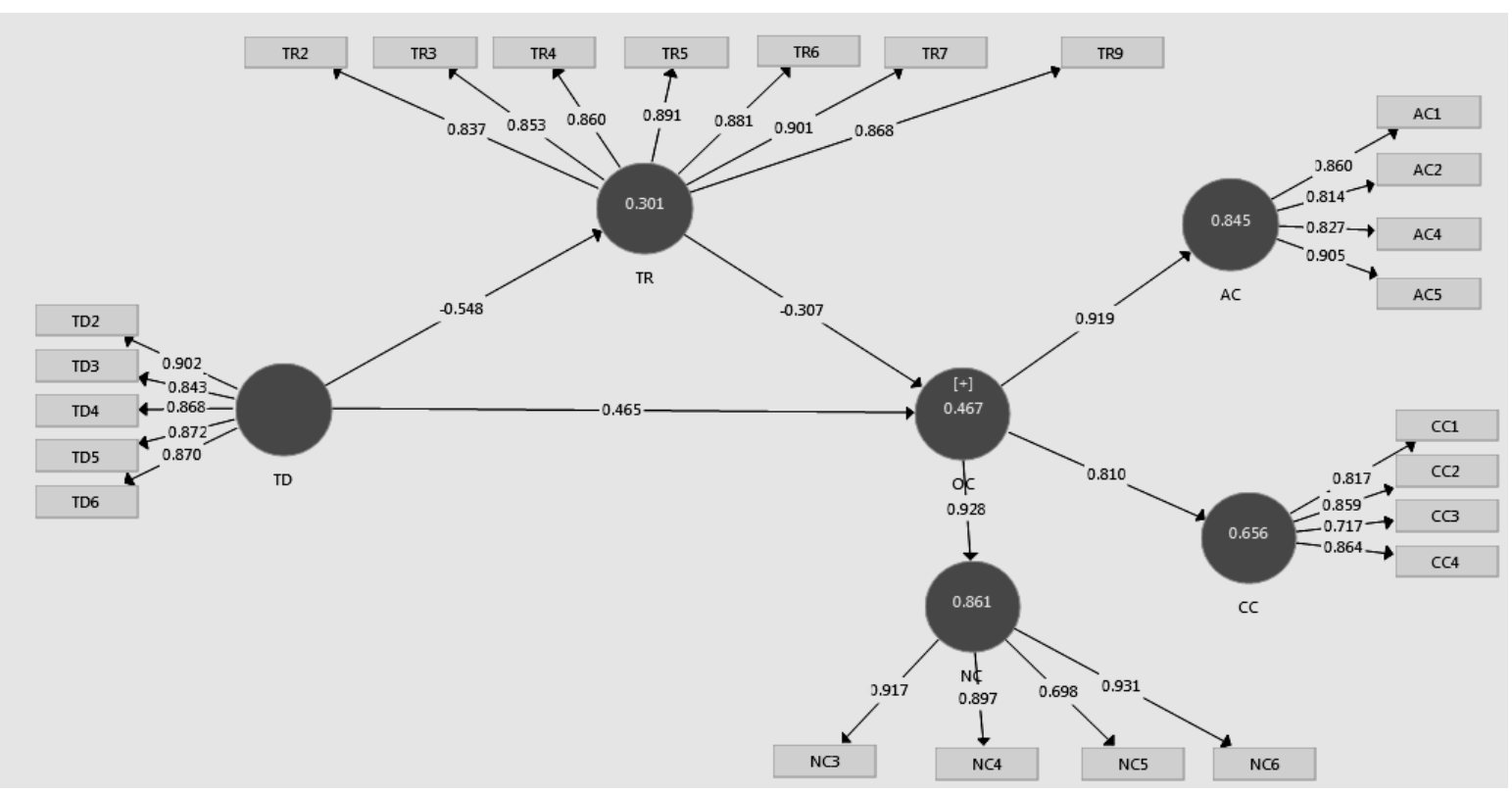

Figure 2 Assessment the Research Mode

$\mathrm{TD}=$ Training and Development; $\mathrm{AC}=$ Affective Commitment; $\mathrm{CC}=$ Continuance Commitment; $\mathrm{NC}=$ Normative Commitment; $\mathrm{OC}=$ Organizational Commitment $\mathrm{TR}=$ Tribalism .

Table 2 Assessment of Measurement Model

\begin{tabular}{|c|c|c|c|c|c|}
\hline Construct & Item & Loadings & $\begin{array}{l}\text { Cronbach's } \\
\text { Alpha }\end{array}$ & $\mathrm{CRa}$ & $A V E^{b}$ \\
\hline $\begin{array}{c}\text { Training } \\
\text { and } \\
\text { Development } \\
\text { (TD) }\end{array}$ & $\begin{array}{l}\text { TD2 } \\
\text { TD3 } \\
\text { TD4 } \\
\text { TD5 } \\
\text { TD6 }\end{array}$ & $\begin{array}{l}0.902 \\
0.843 \\
0.868 \\
0.872 \\
0.87\end{array}$ & 0.921 & 0.94 & 0.759 \\
\hline Tribalism & $\begin{array}{l}\text { TR2 } \\
\text { TR3 } \\
\text { TR4 } \\
\text { TR5 } \\
\text { TR6 } \\
\text { TR7 } \\
\text { TR9 }\end{array}$ & $\begin{array}{l}0.837 \\
0.853 \\
0.86 \\
0.891 \\
0.881 \\
0.901 \\
0.868\end{array}$ & 0.947 & 0.956 & 0.758 \\
\hline $\begin{array}{l}\text { Organizational } \\
\text { commitment } \\
\text { (OC) }\end{array}$ & $\begin{array}{l}\text { AC1 } \\
\text { AC2 } \\
\text { AC4 } \\
\text { AC5 } \\
\text { CC1 } \\
\text { CC2 } \\
\text { CC3 } \\
\text { CC4 } \\
\text { NC3 } \\
\text { NC4 } \\
\text { NC5 } \\
\text { NC6 }\end{array}$ & $\begin{array}{l}0.860 \\
0.814 \\
0.827 \\
0.905 \\
0.817 \\
0.859 \\
0.717 \\
0.864 \\
0.917 \\
0.897 \\
0.698 \\
0.931\end{array}$ & 0.832 & 0.888 & 0.666 \\
\hline
\end{tabular}


The table 3 shows that all the square root of the AVE values exceeded the correlations of the latent construct which approves the discriminant validity. We used the discriminant validity test by measuring the Fornell-Larcker criterion by taking the square root of AVE values. The square root of each latent construct's AVE should be greater than its highest correlation with any other latent construct(Hair Jr et al., 2014).

Table 3 Discriminate Latent Variable correlation

\begin{tabular}{llllll} 
& AC & CC & NC & TD & TR \\
AC & 0.852 & & & & \\
CC & 0.604 & 0.816 & & & \\
NC & 0.812 & 0.622 & 0.866 & & \\
TD & 0.594 & 0.449 & 0.624 & 0.871 & \\
TR & -0.558 & -0.407 & -0.516 & -0.548 & 0.871 \\
\hline
\end{tabular}

\section{Assessment of Structural Model}

The structural model of the current study was subjected to several evaluating step such R-square determination $\left(\mathrm{R}^{2}\right)$, Effect Size $\left(\mathrm{F}^{2}\right)$, Predictive Relevance $\left(\mathrm{Q}^{2}\right)$, and Goodness of fit the Model (GOF) Finally, the bootstrapping was run to test the significance level of the hypothesized relationships in the study model (Hair et al., 2012; Henseler et al., 2009).

As for the $\mathrm{R}^{2}$ value ( $\mathrm{OC}=0.467$, and $T R=0.301$ ) which represents acceptable values of $\mathrm{R}^{2}$ values based on the criterion of Chin (1998); Frank; Miller (1992) and Hair et al., (2014). The effect size of this study ( $\mathrm{TD}=0.284$ ) was a mediator effect, while the $\mathrm{TR}=0.124$ ) was a small effect. The effect size is a method to evaluate how much as a predictor construct has a substantive control on the dependent variable which can be explored in the course of the effect sizes $\mathrm{f}^{2}$ in PLS-SEM (Jacob Cohen, 1988). According to the recommendation of Cohen, (1988), the effect size $\mathrm{f}^{2}$ of $0.02,0.15$, and 0.35, which can be viewed as a gauge for whether a predictor exogenous latent variable has a small, medium, or large influence at the structural level.

The predictive relevance is that the model must be able to adequately predict each endogenous latent construct's indicators (Hair et al., 2011). Therefore, $Q^{2}$ value is obtained by using a blindfolding procedure Fornell and Cha (1994) indicate that if an endogenous construct's cross-validated redundancy measure value (i.e., $\mathrm{Q}^{2}$ ) for a certain dependent latent variable is larger than zero, its latent explanatory constructs exhibit predictive relevance. The findings offer that all the endogenous latent constructs have exhibited predictive relevance, are $\mathrm{Q}^{2}=(\mathrm{OC}=0.244$; and $\mathrm{TR}=0.211)$. To account for the model performance at both the measurement and structural models, it should focus on the overall prediction performance of the model (Henseler \& Sarstedt, 2013; Vincenzo et al., 2011). We can use the Goodness of fit (GOF), the GoF can be calculated by the following formula:

$$
\text { Gof }=\sqrt{\overline{\left(\mathrm{R}^{2}\right.} \times \overline{\mathrm{AVE})}} \quad \text { Gof }=\sqrt{(\overline{0.384} \times \overline{0.732)}}=0.530
$$

To compare the GoF value with the threshold values of GoF suggest by Wetzels et al. (2009), they derived the following GoF criteria. 0.1 is small, 0.25 is medium, and 0.36 is large GoF. It can be concluded that the model's GoF 0.586 was large which suggesting an adequate of the global PLS model validity.

Finally, the bootstrapping was run to test the significance level of the hypothesized relationships in the study mode. Where PLS path approach, multiple regressions were conducted for the main effects, using the PLS bootstrapping output with several 500 bootstrap samples and 292 cases to examine the path coefficients significance (Hair et al., 2014; Henseler et al., 2009).

Based on the results offered in Table 4, it was obvious that the proposed relationship to TD was positive and had a significant direct effect on OC. Hence the hypothesis $\mathrm{H}_{1}$ was supported, while about $\mathrm{TR}$, it was significant and hurt $\mathrm{OC}$, hence the hypothesis $\mathrm{H}_{2}$ was supported. While the proposed relationship, TD, was significant and has a negative direct effect on mediator TR, hence the hypothesis $\mathrm{H}_{3}$ was supported. The results shown in Table 4 show that the indirect mediating effect of TR on the link 
between (TD) and OC. It is clear that TR mediates the relationship between TD and OC with a significant effect. Therefore, it can be concluded that hypothesis 4 is supported.

Table 4 Path Coefficients Testing

\begin{tabular}{|c|c|c|c|c|c|}
\hline NO. Нypo & Hypothesis & Original Sample(O) & $\mathrm{T}$ Values & P Values & Findings \\
\hline $\mathrm{H} 1$ & $\mathrm{TD}->\mathrm{OC}$ & $0.465^{* * *}$ & 7.022 & 0.000 & Supported \\
\hline $\mathrm{H} 2$ & TR $->$ OC & $-0.307^{* * *}$ & 4.806 & 0.000 & Supported \\
\hline H3 & TD -> TR & $-0.548^{* * *}$ & 11.033 & 0.000 & Supported \\
\hline $\mathrm{H} 4$ & TD-> TR->OC & $0.198^{* * *}$ & 4.400 & 0.000 & Supported \\
\hline
\end{tabular}

\section{Discussion}

Based on an overall review of the relevant previous studies, the current study studies the link between several distinguished areas in the administrative sciences and organizational behaviour concerning cultural traditions. This study tried to determine the relationship between training practices, and the OC through the tribalism as a mediating factor in Yemeni Islamic banking sector.

By referring to the hypotheses of this study, the results in Table 4 show that (TD) was significant and had a positive relationship with OC. This corresponds with the studies (Bulut \& Culha, 2010; Ling Shen, 2012; Yap et al., 2009) that training and development facilitate the updating skills, increased commitment. Based on the study model, the direct mediating effect of TR Tribalism was proposed as mediator. The results in Table 4 indicated that the proposed relationship OC and TD were significant and hurt TR. Hence the hypotheses $\mathrm{H}_{2}$ and $\mathrm{H}_{3}$ were supported. Tribalism as a mediator on the relationship between training practices (TD) and OC has a significant effect. This is due to the influence of the mediator as indicated by prior studies. Alesina et al. (2000) showed that a tribal identity has a greater impact on industrial productivity. Also, the literature of behaviours suggested that tribalism identity is negatively related to HRM in organizations (Zoogah, 2016). Manea(1996) found that the tribalism identity of employees impacts their interactions in organizations. In this regard, some tribes in Yemen have a social connection in the form of confederation (Baabbad, 2015).

Thus, findings show that culture has a significant mediating effect between TD and OC. This could be justified through that Tribalism is a major cultural factor in many Arab countries, particularly in Yemen. Where that Tribalism in Yemen is responsible for underdevelopment and corruption, serving a great obstacle that stands in the way of democracy and socio-economic development (Baabbad, 2015; Fattah, 2011). It is argued that with the presence of tribalism, the commitment and loyalty to tribe will be greater than the commitment and loyalty to the country or organization (Manea, 1996).

\section{Conclusion}

Organizational Commitment has been considered as an important topic which attracts the attention of both practitioners and academicians who studied the changes in the behavioural and organizational of business organizations. It is essential to pay enough attention to the issue of commitment in organizations because it helps to maintain stability. It also helps the organization to achieve high-quality performance. In this study, the influence of tribalism culture as a mediating variable between in Training practices on OC in the Yemeni Islamic banks was explored. Tribalism plays a crucial role in Yemen which in turn leads to positive and negative effects on involvement and commitment of the employees. It possibly threatens the independence of the training practices which assists in finding ways to ensure of motivating employees on organizational commitment. Thus, this study was contributed to the present literature by many ways like investigating the impact of training practices on OC in developing countries, particularly Yemen, and examining the mediating effect of culture (Tribalism) on the relationship between Training practices and OC. 


\section{References}

A.Foote, D. (2005). Employee commitment and organizational policies. Management Decision, 43(2), $203-219$.

Acton, T., \& Golden, W. (2002). Training: The Way to Retain Valuable IT Employees? InSITE - "Where Parallels Intersect," (June), 1-12.

Al-dawsari, N. (2012). Tribal Governance and Stability in Yemen. Carnegie Endowment for International Peace, 1-26.

Aladwan, K., Bhanugopan, R., \& D'Netto, and B. (2015). The effects of human resource management practices on employees' organisational commitment. International Journal of Organizational Analysis, 23(3), 472-492.

Alesina, A., Spolaore, E., \& Wacziarg, and R. (2000). Economic Integration and Political Disintegration The. American Economic Review, 90(5), 1276-1296.

Allen, D. G., Shore, L. M., \& Griffeth, R. W. (2003). The Role of Perceived Organizational Support and Supportive Human Resource Practices in the Turnover Process. Journal of Management, 29(1), 99-118.

Allen, N. J., \& John, P. M. (1990). The measurement and antecedents of affective, continuance and normative commitment to the organization. Journal of Occupational Psychology, 63(1), 1-18.

Allen, N. J., \& Meyer, J. P. (1993). Organizational commitment: Evidence of career stage effects? Journal of Business Research, 26(1), 49-61.

Allen, N. J., \& Meyer, J. P. (1996). Affective, Continuance, and Normative Commitment to the Organization: An Examination of Construct Validity. Journal of Vocational Behavior, 49(3), 252-276.

Altarawneh, I. (2009). Training and Development Evaluation in Jordanian Banking Organisations, Research and Practice in Human Resource Management. Research and Practice in Human Resource Management, 17(1), 1-23.

Baabbad, M. (2015). The influence of regulatory sanctions and Tribalism on perceived auditor independence: the Yemeni evidence.

Brandt, M. (2017). Tribes and politics in Yemen: A History of the Houthi conflict. Oxford University Press.

Bulut, C., \& Culha, O. (2010). The effects of organizational training on organizational commitment. International Journal of Training and Development, 14(4), 309-322.

Cavana, R. Y., Delahaye, B. L., \& Sekaran, U. (2001). Applied business research: Qualitative and quantitative methods. John Wiley \& Sons Inc.

Chan, J. C. C. C. A. (2008). International Journal of Manpower Human resource practices, organizational commitment and intention to stay. International Journal of Manpowe, 29(6), 503-522.

Chew, J., \& Chan, C. C. A. (2008). Human resource practices, organizational commitment and intention to stay. International Journal of Manpower, 29(6), 503-522.

Cohen, A. (2003). Multiple Commitments in the Workplace An Integrative Approach. Journal of Chemical Information and Modeling.

Cooper, D. R., \& Schindler, \& P. S. (2006). Business research methods, McGraw-Hill/Irwin New York. , Eleventh Edition.

Corstange, D. (2008). Tribes and the Rule of Law in Yemen. In Annual Conference of the Middle East Studies Association, Washington (pp. 22-25).

Coyle-Shapiro, J. a-M. J., \& Conway, N. (2005). Exchange relationships: Examining psychological contracts and perceived organizational support. Journal of Applied Psychology, 90(4), 774-781.

Delery, J. E., \& Doty, D. H. (1996). Modes of Theorizing in Strategic Human Resource Management: Tests of Universalistic, Contingency, and Configurational Performance Predictions Author ( s ): John E . Delery and D. Harold Doty Published by Academy of Management Stable URL: http://www. The Academy of Management Journal, 39(4), 802-835.

El-Jardali, F., Merhi, M., Jamal, D., Dumit, N., \& Mouro, G. (2009). Assessment of nurse retention challenges and strategies in Lebanese hospitals: The perspective of nursing directors. Journal of Nursing Management, 17(4), 453462.

Fattah, K. (2011). Tribes and tribalism in the Arab Spring. Yemen Times, 26, 1-4.

Fernandes Valérie. (2012). (Re) Discovering the PLS approach in management science. M@ N@ Gement, 15(1).

Fiona Edgar and Alan Geare. (2005). HRM practice and employee attitudes: different measures - different results Fiona Edgar Alan Geare. Personnel Review, 34(5), 534-549.

Frank, L. R., \& and Goulet Margaret L. (2002). Organizational commitment across three sectors: public, non-profit, and for profit. Public Personnel Management, 31(2), 201-210.

Glaser, S. R., Zamanou, S., \& and Hacker Kenneth. (1987). Measuring and Interpreting Organizational Culture. Management Communication Quarterly, 1(2), 173-198.

Gouldner, A. W. (1960). The Norm of Reciprocity: A Preliminary Statement. American Sociological Review, 25(2), 161178.

Hair, J. F., Ringle, C. M., \& Sarstedt, M. (2011). PLS-SEM: Indeed a Silver Bullet. The Journal of Marketing Theory and Practice, 19(2), 139-152. 
Hair, J. F., Sarstedt, M., Ringle, C. M., \& Mena, J. A. (2012). An assessment of the use of partial least squares structural equation modelling in marketing research. Journal of the Academy of Marketing Science, 40(3), 414-433.

Hair Jr, J., Sarstedt, M., Hopkins, L., \& G. Kuppelwieser, V. (2014). Partial least squares structural equation modelling (PLS-SEM) An emerging tool in business research. European Business Review, 26(2), 106-121.

Henseler, J. RG, Ringle, C. M., \& Sinkovics, and R. R. (2009a). The use of partial least squares path modelling in international marketing. New Challenges to International Marketing (Advances in International Marketing, 20(1), 277319.

Henseler, J., \& Sarstedt, M. (2013). Goodness-of-fit indices for partial least squares path modelling. Computational Statistics, 28(2), 565-580.

Henseler, Ringle, Christian M., \& and Sinkovics, R. (2009). The use of partial least squares path modelling in international marketing. In New Challenges to International Marketing, 20, 277-319 Emerald Group Publishing Limited.

Hofstede, G., Hofstede, G. J., \& Minkov, M. (1997). Cultures and Organizations: Software of the Mind, Intercultural.

Imran, H., Arif, I., Cheema, S., \& Azeem, M. (2014). Relationship between Job Satisfaction, Job Performance, Attitude towards Work, and Organizational Commitment. Entrepreneurship and Innovation Management Journal, 2(2), 135144.

Jacob Cohen. (1988). Statistical power analysis for the behavioural sciences $2 n d$.

Lamba, S., \& Choudhary, N. (2013). Impact of Hrm Practices on Organizational Commitment of Employees. International Journal of Advancement in Research and Advancement, 2(4), 407-423.

Ling Ling Tao Qing Peng Shen. (2012). Can training promote employee organizational commitment? The effect of employability and expectation value. Nankai Business Review International, 5(2), 162-186.

Manea, E. M. (1996). Yemen, the Tribe and the State. (pp. 10-11).. In International Colloquium on Islam and Social Change, University of Lausanne, 10-11.

Meyer, J., \& Allen, N. J. (1997). Commitment in the Workplace: Theory, Research and Application. SAGE Publications, Thousand Oaks.

Meyer, J. P., \& Allen, N. J. (1991). A three-component conceptualization of organizational commitment. Human Resource Management Review, 1(1), 61-89.

Meyer, J. P., Stanley, D. J., Herscovitch, L., \& Topolnytsky, L. (2002). Affective, Continuance, and Normative Commitment to the Organization: A Meta-analysis of Antecedents, Correlates, and Consequences. Journal of Vocational Behavior, 61(1), 20-52.

Nik Mutasim Nik, \& Sharmin Shahid. (2009). Islamic HRM Practices and Employee Commitment ?: A Test Among Employees of Islamic Banks in Bangladesh. Graduate School of Business, Universiti Kebangsaan Malaysia, 12691278.

Palmer, L. (2006). The Impact of Human Resource Management Practices on Employee's Commitment in The Banking Sector in Kingston, Jamaica", PhD Thesis, School of Business and Entrepreneurship, University of Nova South-easternpdf.

Payne, S. C., \& Huffman, A. H. (2005). A longitudinal examination of the influence of mentoring on organizational commitment and turnover. Academy of Management Journal, 48(1), 158-168.

Pedhazur, E. J. (1997). Multiple regression in behavioural research. New York Harcourt Brace College Publishers (Vol. 3).

Peterson, J. E. (2008). Tribes and Politics in Yemen Yemen's.

Qiao, K., Luan, X., \& Wang, X. (2008). HRM practices and organizational commitment: A study about its employees from Chinese private-owned enterprises. 2008 International Conference on Wireless Communications, Networking and Mobile Computing, WiCOM 2008, (20072193), 1-6.

R. Frank; Miller, N. B. A. (1992). A primer for soft modelling. Akron, OH, US. University of Akron Press.

Ringle, Christian M., Wende, Sven, \& Becker, J.-M. (2014). SmartPLS 3.0 Hamburg: SmartPLS. Retrieved. From Http://Www.Smartpls.Com.

Robinson, G. E., Wilcox, O., Carpenter, S., \& Al-Iryani, A. (2006). Yemen corruption assessment. United States Agency For International Development.

Sager, J. K. ., \& Johnston, M. W. (1989). Antecedents and outcomes of organizational commitment: A study of salespeople. Journal of Personal Selling \& Sales Management, 9(1), 30-41.

Sekaran, U. (2003). Research methods for business A Skill-Building Approach Fourth Edition Uma. Journal of Chemical Information and Modeling (Vol. 53).

Sekaran, U., \& and Roger Bougie. (2010). Research methods for business: A skill building approach (5 the ed.). Chichester.

Suliman, A. and P. I. (2000). Is Continuance Commitment Beneficial To Organization Commitment-Performance Relationship: A New Look". Journal of Managerial Psychology, 15(5), 407.

Tajfel, H., \& Turner, J. (1979). An Integrative Theory of Intergroup Conflict. The Social Psychology of Intergroup Relations.

Tzafrir, S. S. (2006). A universalistic perspective for explaining the relationship between HRM practices and firm 
performance at different points in time. Journal of Managerial Psychology, 21(2), 109-130.

Victoria, B. (2006). The relationship between HRM practices and service behaviour in South African service organizations. International Journal of Human Resource Management, 17(7), 1321-1338.

Vincenzo Esposito Vinzi Wynne W. Chin Jörg Henseler Huiwen Wang. (2011). Springer Handbooks of Computational Statistics Series Editors. Methods.

Wetland, D. (2003). The strategic training of employees model: balancing organizational constraints and training content. S.A.M. Advanced Management Journal, 86(1), 56-63.

Wetzels, M., Schröder, G., \& Oppen, and C. (2009). Using pls path modelling for assessing hierarchical construct models : guidelines and empirical. MIS Quarterly, 33(1), 177-195.

Wynne W. Chin. (1998). The partial least squares Approach to Structural Equation Modeling. Modern Methods for Business Research, 295-358.

Yamao, S., \& Sekiguchi, T. (2015). Employee commitment to corporate globalization: The role of English language proficiency and human resource practices. Journal of World Business, 50(1), 168-179.

Yap, M., Holmes, M. R., \& Cukier, \& C.-A. H. W. (2009). The relationship between diversity training, organizational commitment, and career satisfaction. Journal of European Industrial Training, 34(6), 519-538.

Zaitouni, M., Sawalha, N. N., \& Sharif, A. (2011). The Impact of Human Resource Management Practices on Organizational Commitment in the Banking Sector in Kuwait. International Journal of Business and Management, 6(6), 108-123.

Zoogah, D. B. (2016). Tribal diversity, human resources management practices, and firm performance. Canadian Journal of Administrative Sciences/Revue Canadienne Des Sciences de l'Administration, 33(3), 182-196, 33(3), $182-196$.

\section{Appendix (1) Dimension Tribalism}

In my bank, my tribe identity is an obstacle to confront problems constructively.

In my bank, my tribe identity is an obstacle to work cooperatively.

In my bank, my tribe identity is an obstacle to work with resolving disagreements cooperatively. (Glaser,

In my bank, my tribe identity is an obstacle to work directly and honestly with my workmates. Susan;

In my bank, my tribe identity is an obstacle for getting an atmosphere of trust. Zamanou

In my bank, because of my tribe identity, not counted.

, 1987)

In my bank, because of my tribe identity, my ideas are not valued.

In my bank, because of my tribe identity, I feel like not being part of the family.

In my bank, because of my tribe identity, I seldom asked to suggest how to make my job better. 